\title{
The morphological characteristics of the physically abused child. Report of a case and literature review
}

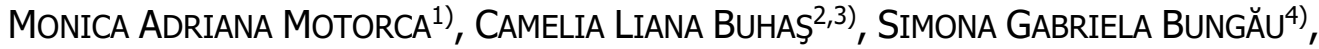

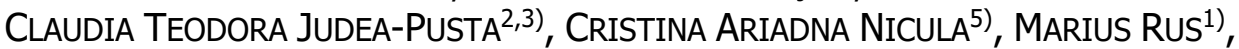

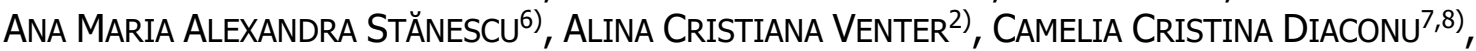 \\ PAULA MARIAN ${ }^{1)}$
}

\author{
1) Department of Medical Disciplines, Faculty of Medicine and Pharmacy, University of Oradea, Romania \\ 2) Department of Morphological Disciplines, Faculty of Medicine and Pharmacy, University of Oradea, Romania \\ 3) Forensic Service of Bihor County, Oradea, Romania \\ 4) Department of Pharmacy, Faculty of Medicine and Pharmacy, University of Oradea, Romania \\ 5) Department of Ophthalmology, Iuliu Hatieganu University of Medicine and Pharmacy, Cluj-Napoca, Romania \\ 6) Department of Family Medicine, Carol Davila University of Medicine and Pharmacy, Bucharest, Romania \\ 7) Department 5, Carol Davila University of Medicine and Pharmacy, Bucharest, Romania \\ 8) Clinic of Internal Medicine, Emergency Clinical Hospital of Bucharest, Romania
}

\begin{abstract}
Child abuse remains a current problem, despite progress in the field of prevention and social assistance. The injuries produced by physical abuse have to be evaluated using scientific methods, in order to be considered as evidences later in Court, but also to ensure the physical and social security of the child. Among the morphological characteristics of the child (on which depends how the lesions are formed, differently in children from adults), there is the strong adherence of the dura mater to the skull bones, this fact preventing the formation of extradural hematomas. Another special aspect is the poor development of skeletal muscle before puberty, which confers poor protection of the internal organs against the traumatic physical agents. This paper presents the particular morphological and histological aspects that can be evidenced by forensic autopsy in children. The study was conducted on a female child, physically assaulted, arrived in the emergency department of the hospital. The death occurred shortly after hospitalization. The investigations revealed multiple external (on the whole body) and internal injuries. According to the statements of those who called the ambulance, the injuries occurred because of falling on the stairs and were considered by the family as being superficial, without requiring medical care. The forensic autopsy, through the external, internal and histopathological examination, highlighted the specific injuries that led to the death, thereby contributing to the elucidation of the tanatogenerative mechanism, of the way the lesions were produced and to the applying the law.
\end{abstract}

Keywords: physical abuse, ecchymoses, hematomas, histopathological examination, tanatogenerative mechanism.

\section{Introduction}

In Romania, physical punishment is still widely used to discipline children, in some countries this being prohibited by law long ago [1]. The causes that lead to physical abuse of the child are multiple, from dysfunctional or separated families to drug or alcohol use $[2,3]$. Some statistics estimate that worldwide there are about 3 million children abused annually [4].

Child abuse has many forms: physical abuse (hand or foot hitting, shaking, burning, etc.), sexual abuse (persuasion, forcing or engaging the child in sexual activities, fondling, penetration, and exposing a child to other sexual activities), emotional abuse (refers to the child's personal devaluation or emotional well-being, such as: using nicknames, shaming the child, rejecting, not showing affection for the child, threats, etc.). Another form of abuse is neglect, which includes not meeting the basic physical and emotional needs of the child. These needs include housing, food, clothing, education and access to health care [5].

In the case of physical abuse, accidental injuries and those caused by aggression must be differentiated [6]. This is necessary and essential to prove the reality of physical abuse in Court. Generally, the existence of ecchymoses located on the ears, neck, face, head or on the parts of the body where there are no prominent bones advocates for physical aggression (physical abuse) [7, 8]. Extremely rarely, in the event of death, traumatic marks can mimic abuse, the cause of death being pathological or intoxication with various toxic substances [9-12].

Child abuse can have consequences in the adult period in the way that it may increase the risk of developing chronic diseases (e.g., high blood pressure) [13-15]. Also, childhood maltreatment can lead to long-term changes in the functioning of the brain, through the deoxyribonucleic acid (DNA) methylation process [16, 17]. On the other hand, some studies show that if the mother was victim of physical abuse during her own childhood, the risk of becoming abusive increases, with a percentage of $72 \%$ in the case of a single episode of abuse and by $300 \%$ in the case multiple episodes of abuse [18].

The major form of physical abuse is murder. Children less than five years of age represent the second most

This is an open-access article distributed under the terms of a Creative Commons Attribution-NonCommercial-ShareAlike 4.0 International Public License, which permits unrestricted use, adaptation, distribution and reproduction in any medium, non-commercially, provided the new creations are licensed under identical terms as the original work and the original work is properly cited. 
frequent risk group (after the age group of 15-19) in terms of the frequency of killings. In rural areas, girls are killed more frequently, the mother usually being the author of the murder [19]. The most common lesions (encountered in children who died from physical abuse) or which have a very serious evolution are located at the brain level (95\%) or are represented by multiple ecchymoses (beaten child syndrome) in $90 \%$ of cases [20]. The most common mechanism for producing the lesions causing death is striking with blunt bodies (53.4\%), followed by choking/strangulation $(20.2 \%)$ or the use of sharp objects $(13 \%)$. The most common topographic regions targeted are neurocranium (62.2\%) and viscerocranium (front) (60.2\%). Neurogenic shock, asphyxia and hemorrhagic shock are the most common tanatogenerative mechanisms [21]. Some other times, the delayed death is consecutive of septic complications that occur in the evolution of traumas [22].

\section{Aim}

In this study, a case of polytrauma followed by death in a 3-year-old child was analyzed. There were highlighted the morphological particularities of the child at this age and the way they influence the formation, severity and evolution in time of post-traumatic lesions.

\section{Case presentation}

PCS, 3-year-old, female, from Oradea, Romania was left by the mother in the care of some neighbors. The mother was separated from the father and the father left abroad. The woman also had in care a boy, older, from another relationship, and because of the financial problems could not support the minor girl. The neighbors volunteered to take care of the girl. On June 28, 2015, the neighbors who were taking care of the minor called the ambulance motivating that the girl "feels bad". At the arrival of the ambulance, the neighbors claimed that the girl fell on the stairs two days before, but they considered that it was not necessary to take her to the hospital, because she was "lively". The anamnesis performed at the hospital did not reveal personal or heredocolateral history for the minor. At the objective examination, multiple post-traumatic injuries were found all over the body. The girl was hospitalized. Shortly after admission, the child died. The police considered the case a suspicious death and asked for the forensic autopsy. Investigators requested the forensic autopsy to determine the cause and conditions of the death.

\section{Forensic autopsy}

The external examination of the corpse revealed a child with height and weight corresponding to the age, height $92 \mathrm{~cm}$, weight $14.5 \mathrm{~kg}$, with normally represented muscleadipose tissue, presenting multiple ecchymoses, wounds and excoriated placards at the level of the head, trunk and limbs. Thus, at the neuro- and viscerocranium level, there were: several purple-colored ecchymoses at the occipital, frontal and ear regions, with dimensions between $1.1 / 0.7 \mathrm{~cm}$ and $5 / 3 \mathrm{~cm}$ and at the level of the right cheek another brown-colored ecchymosis, with dimensions of $1.3 / 1 \mathrm{~cm}$; at the lower lip, on the external face, a contusion wound with dimensions of $2 / 0.5 \mathrm{~cm}$, and on the vestibular faces of both lips more mucosal continuity solutions; upper incisor teeth with pathological mobility; swollen nasal pyramid with multiple excoriations at this level; excoriations covered with detaching hematopoietic crusts corresponding to the horizontal branch of the mandible. At the trunk level, there were: multiple purple-colored ecchymoses on the anterior and posterior face of the thorax, with dimensions between $1 / 1 \mathrm{~cm}$ and $3 / 2 \mathrm{~cm}$; multiple yellowish-brown ecchymoses in the lumbar region, with dimensions between $2 / 1 \mathrm{~cm}$ and 3.5/1.5 cm; multiple purple ecchymoses, some of them confluent in the sacral region, with dimensions between $2 / 1 \mathrm{~cm}$ and $6 / 4 \mathrm{~cm}$. At the abdomen level, there were several ecchymoses of different colors from violet to yellow and fine excoriations with dimensions between $4 / 3 \mathrm{~cm}$ and $6 / 4 \mathrm{~cm}$ and a yellowish-brown ecchymosis in the pubic region, with dimensions of $2 / 1.2 \mathrm{~cm}$. At the level of the upper limbs, there were: multiple ecchymoses of different colors from violet to violet-brown and brown on the arms and forearms, with dimensions up to $6 / 5 \mathrm{~cm}$; a purple-colored ecchymosis on the right elbow and multiple excoriations and bruises on the hands with dimensions up to $4.5 / 1 \mathrm{~cm}$. At the level of the lower limbs, there were: purple ecchymoses on both knees; ecchymoses at the level of the calves, one being of elongated form, yellow in color, with dimensions of $3 / 0.5 \mathrm{~cm}$; purplecolored ecchymoses in the malleolar regions, with dimensions between $1 / 0.6 \mathrm{~cm}$ and $4 / 3.5 \mathrm{~cm}$ (Figure 1-3).

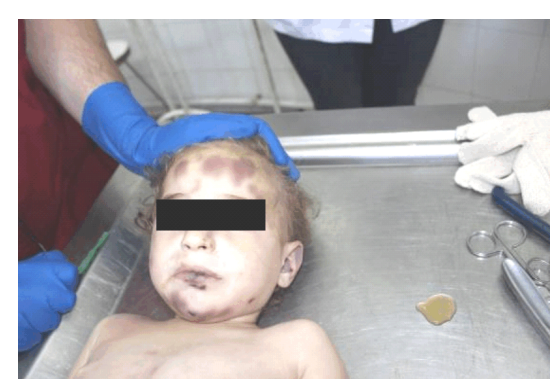

Figure 1 - The bruises on the face.

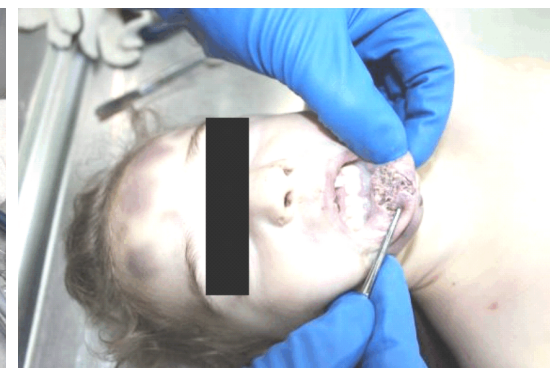

Figure 2 - Lower lip wounds (oral vestibule).

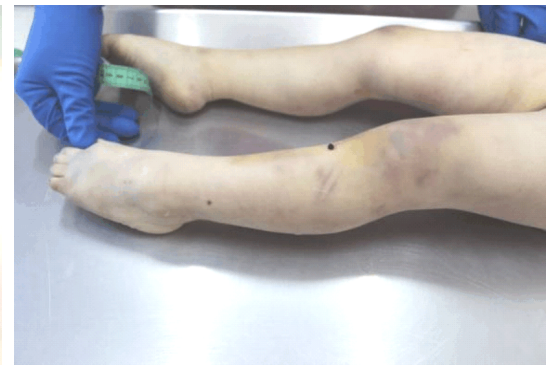

Figure 3 - The bruises on the lower limbs, with different shapes, colors and ages.
The internal examination of the corpse revealed: multiple hematic infiltrates at the level of the soft epicranial tissues; linear fracture in the occipital bone; small extradural hematoma; brain edema; multiple rib fractures and hematic infiltrates at the level of the chest wall; approximately $75 \mathrm{~mL}$ reddish blood in the pleural cavities; lungs with purple-colored areas alternating with reddish-colored areas and intersecting with multiple violet-colored petechiae; 
hemoperitoneum consisting of liquid blood in an amount of about $300 \mathrm{~mL}$ and a purple blood clot of about $100 \mathrm{~mL}$ (Figure 4); rupture of the mesentery, with interest for arterial vessels and surrounding hematopoietic infiltrates; contusion in the diaphragm and a subcapsular hepatic hematoma; pancreatic contusion; hematic infiltrate in both kidneys; hematic infiltrate at the level of the right adrenal gland.

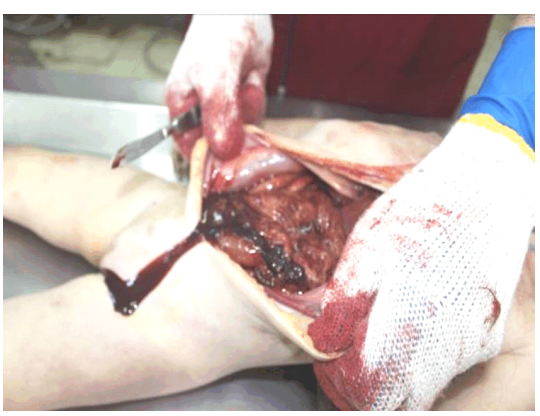

Figure 4 - Hemoperitoneum secondary to rupture of arterial vessels in the mesentery.

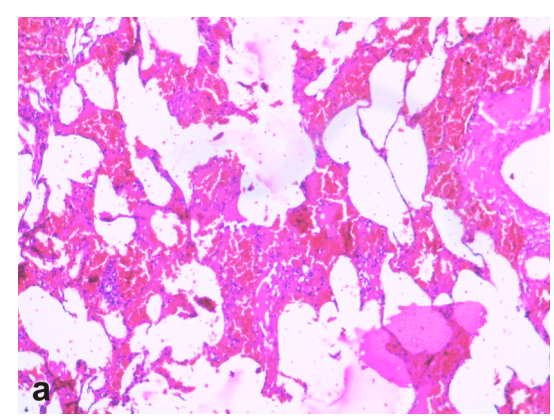

Figure 6 - ( $a$ and b) Microscopic aspects showing areas of pulmonary hematopoietic aspiration. HE staining: (a) $\times 200$; (b) $\times 400$.
During the autopsy, organ fragments were collected for histopathological (HP) examination. Hematoxylin-Eosin (HE) staining was used. The HP examination revealed: pericellular and perivascular edema, cerebral stasis (Figure 5, $\mathrm{a}$ and $\mathrm{b}$ ); flaking of alveolar epithelium, blood infiltrate into alveoli and bronchioles (appearance of hematic aspirate) (Figure 6, a and b) contusion with hematic infiltrate into pancreatic parenchyma (Figure 7).
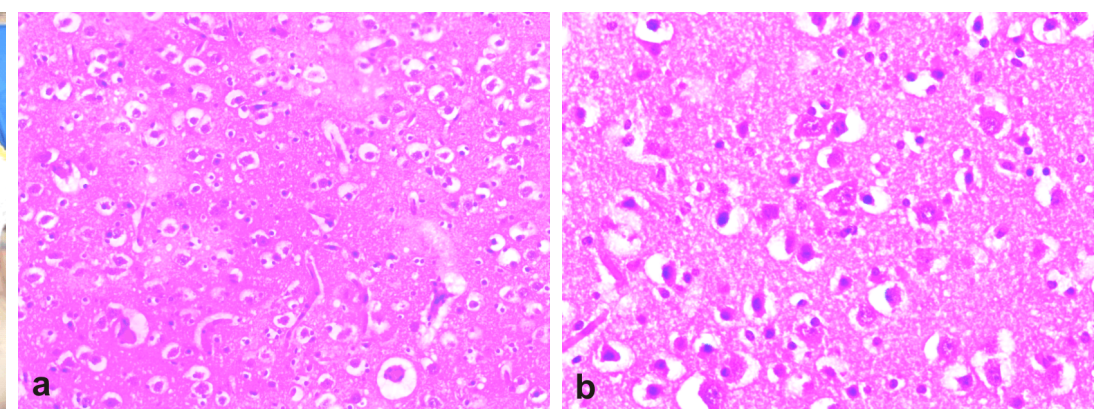

Figure 5 - (a and b) Microscopic aspects showing areas of cerebral parenchyma affected by perineuronal and perivascular edema. HE staining: (a) $\times 100$; (b) $\times 200$.
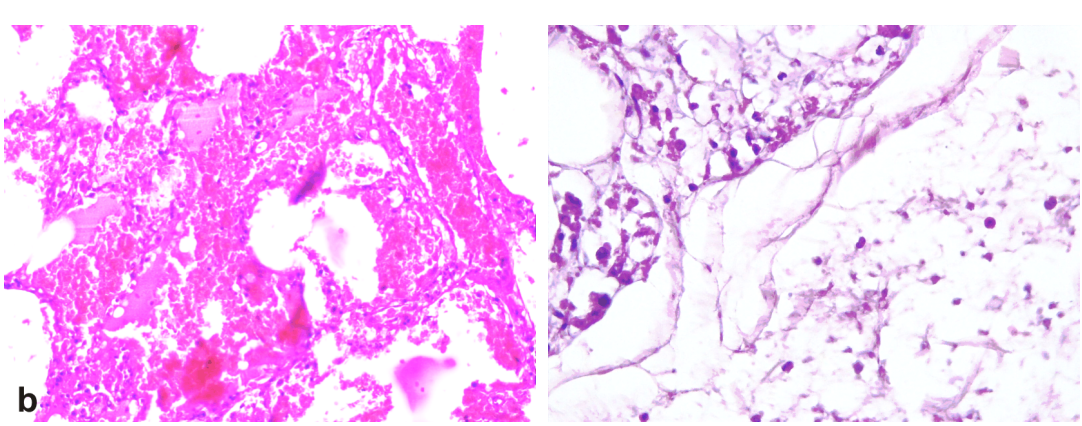

Figure 7 - An area of the pancreas with zones of hematic infiltration localized in the parenchyma (HE staining, $\times 400)$.

\section{ㅁ Discussions}

The forensic autopsy revealed that the death of the child was violent. It was due to the traumatic and hemorrhagic shock, which occurred in the evolution of a polytrauma with skull fracture, multiple rib fractures, hemoperitoneum, rupture of the mesentery arteries, pancreatic contusion. The injuries through violence (found during the autopsy) were caused by hitting with/by hard bodies, some of them possible in a fall on the stairs, with the hitting of the victim's body against the rough uneven surface of the stairs, with their elevations. Hematopoietic infiltrates of the pericranial soft tissues located bilaterally parietally, and the characteristics they present, may advocate for the compression of the pericranial soft tissues between two hard surfaces (the bone patch and the pulp of the fingers), but neither the hitting with/by hard bodies can be excluded. Between the death of the child on June 28, 2015 and the injuries described during the autopsy, there is a direct, unconditional causal link.

After the autopsy and the investigations carried out, the mother of the child and the neighbors were convicted. The court ruled that they should be sentenced for death causing injuries and ill-treatment applied the minor.

The victim presents multiple injuries produced by striking with/against blunt objects, respectively bruises, wounds, blood infiltrates in the soft parts, bone fractures, contusions and ruptures of the internal organs. Most lesions are situated at the level of the cephalic extremity, according to the literature data [20]. Some lesions are produced by falling, respectively those at the elbows and knees, locations described as common for this mechanism in other studies too $[7,8]$.

The morphological peculiarities of the 3-year-old child, which make the evolution of the lesions different from that of the adult, are: strong adhesion of the dura mater from the bones of the skull that prevents the formation of large extradural hematomas, with compressive effect on the brain, clinically manifested by focal symptoms. In children, the dura mater is more strongly attached to the skull because it is attached by sutures, whereas in the adult it becomes separated from these [23]. The case studied presented the fracture of the bones of the skull with extradural hematoma, but it was not voluminous, the child did not present focal phenomena that would cause the evolution of the state of health to become very serious immediately after the trauma, being possible to survive for two days, without medical treatment.

In the presented case, the ecchymoses highlighted on the body at autopsy are of different colors, which show different dates of their production, considering the hemoglobin metabolism [24]. Their asymmetrical disposition, 
the presence on large surfaces of the body, as well as the irregular shape, suggest that different blunt objects caused them. The injuries of internal organs (brain, mesentery, liver, diaphragm, pancreas, perirenal tissues) suggest a high intensity of impact force application. In the occurrence of lesions at internal organs level, however, another morphological peculiarity of the young child was important, namely the poor development of the skeletal musculature; this did not provide effective protection of the internal organs against the received blows, a lower force of impact being sufficient for the occurrence, frequency and severity of the lesions found, compared to the force needed to produce similar lesions in the adult.

The death was due to the traumatic and hemorrhagic shock that occurred in the evolution of a polytrauma with cranial fracture, multiple rib fractures, hemoperitoneum, ruptures of mesentery arteries, pancreatic contusion. In addition, the wounds on the lips and the incisor avulsion prevented the normal nutrition and hydration of the child during the two days from the production of the trauma until the announcement of the emergency crew, a factor favoring the death occurring.

Among the causes reported in the literature as death causes in young children are head trauma through the use of blunt objects and trauma of the abdominal organs, through the same mechanism [25]. A common marker of head trauma in children under five is retinal hemorrhage revealed in $70 \%$ of brain trauma [26]. In the presented case, there were both head trauma with fracture of the skull and extradural hematoma, as well as trauma of the abdominal organs, respectively liver, pancreas and mesentery. However, retinal hemorrhage was not revealed.

Cases of violence against children have serious consequences for society. Therefore, in order to investigate and prevent them, the justice representatives, the medical professionals and specialists in the social protection services need to collaborate [27]. The difficulty in preventing violence against children is because child abuse is underreported [28], and the authorized organs find about abuses only in the case of serious ones, that require hospitalizetion, or when the child dies. In this case, the caregivers of the child tried to hide the aggression, kept the traumatized child at home, without announcing the ambulance, which led to the death by failing to provide the necessary medical care in time. They have thus tried to avoid liability to the law in force regarding the protection of the child against abuse, neglect, exploitation and any form of violence [29].

In Romania, most commonly, children less than three years of age are killed by the mother, in $65 \%$ of the cases, especially by hitting with hard bodies, using sharp objects, strangulation or starvation. Other international studies report that victims are mostly boys [30]. In cases of extrafamilial murder of children, these are often done by men, many of them diagnosed or not with mental disorders $[31,32]$.

Due to the poor development of skeletal muscle at this early age, physical force is preferred, which, even without high intensity, can lead to the death of the child. Also, for the same reason, death occurs due to starvation of the child [33].

The particularities of the presented case are given by several aspects: the fact that the aggressor is not the mother (one of the parents) of the victim, but other people (neighbors); in the mechanism of death, besides the physical trauma produced by hitting with hard blunt bodies, another mechanism, less commonly encountered, namely starvation (as a secondary consequence of traumas at the level of the oral cavity, which prevented the proper feeding, favoring the aggravation of the health status of the child) was involved.

\section{Conclusions}

Aggression on minors is a reality in many countries, including Romania. The paper presents the morphological particularities specific to children less than three years old, subjected to repeated physical abuse. Precisely, these particularities made the post-traumatic evolution of the studied case atypical, allowing the survival for a period of time. Both serious injuries (resulting from repeated physical abuse, as mentioned above) and the impossibility of normal feeding (due to oral injuries and digestive difficulties, secondary to pancreatic contusion and mesentery rupture) leaded to death. The HP examination, together with the history and the conclusions of the autopsy, were able to provide certain diagnostic features, established the tanatogenerative mechanism and the way of producing the lesions, allowing to obtain concrete evidence in order to apply the law against the aggressors.

\section{Conflict of interests}

The authors declare that they have no conflict of interests. All authors read and approved the final manuscript.

\section{Authors' contribution}

Monica Adriana Motorca, Claudia Teodora Judea-Pusta and Cristina Ariadna Nicula equally contributed to this article.

\section{References}

[1] Archard D. Child abuse: parental rights and the interests of the child. J Appl Philos, 1990, 7(2):183-194. https://doi.org/ 10.1111/j.1468-5930.1990.tb00266.x

[2] Felitti VJ, Anda RF, Nordenberg D, Williamson DF, Spitz AM, Edwards V, Koss MP, Marks JS. Relationship of childhood abuse and household dysfunction to many of the leading causes of death in adults: The Adverse Childhood Experiences (ACE) Study. Am J Prev Med, 1998, 14(4):245-258. https://doi.org/10.1016/s0749-3797(98)00017-8 PMID: 9635069

[3] Embleton L, Lee H, Gunn J, Ayuku D, Braitstein P. Causes of child and youth homelessness in developed and developing countries: a systematic review and meta-analysis. JAMA Pediatr, 2016, 170(5):435-444. https://doi.org/10.1001/jama pediatrics.2016.0156 PMID: 27043891 PMCID: PMC5497301

[4] Swerdlin A, Berkowitz C, Craft N. Cutaneous signs of child abuse. J Am Acad Dermatol, 2007, 57(3):371-392. https:// doi.org/10.1016/j.jaad.2007.06.001 PMID: 17707148

[5] Fortson BL, Klevens J, Merrick MT, Gilbert LK, Alexander SP. Preventing child abuse and neglect: a technical package for policy, norm, and programmatic activities. Division of Violence Prevention, National Center for Injury Prevention and Control, Centers for Disease Control and Prevention, Atlanta, GA, USA, 2016, available at: https://www.cdc.gov/violenceprevention/ pdf/can-prevention-technical-package.pdf (accessed: October 20, 2019).

[6] Mekereş F, Buhaş CL. Spontaneous human combustion, homicide, suicide or household accident. Rom J Leg Med, 2016, 24(1):11-13. https://doi.org/10.4323/rjlm.2016.11

[7] Pierce MC, Kaczor K, Aldridge S, O'Flynn J, Lorenz DJ. Bruising characteristics discriminating physical child abuse from accidental trauma. Pediatrics, 2010, 125(1):67-74. https:// doi.org/10.1542/peds.2008-3632 PMID: 19969620 
[8] Maguire S, Mann MK, Sibert J, Kemp A. Are there patterns of bruising in childhood which are diagnostic or suggestive of abuse? A systematic review. Arch Dis Child, 2005, 90(2): 182-186. https://doi.org/10.1136/adc.2003.044065 PMID: 15665178 PMCID: PMC1720260

[9] Woydt L, König C, Bernhard MK, Nickel P, Dreßler J, Ondruschka B. The importance of laboratory re-evaluation in cases of suspected child abuse - a case report. Leg Med (Tokyo), 2017, 28:27-30. https://doi.org/10.1016/j.legalmed. 2017.07.007 PMID: 28755627

[10] Buhas CL, Buhas BA, Daina LG, Hanganu B, Manoilescu IS, Judea Pusta CT, Hlescu AA, Mircea C, Somlea MC, Marian P, loan BG. Multiple fatal intoxications caused by improper consumption of an alcoholic para-pharmaceutical product. Rev Chim (Bucharest), 2019, 70(7):2471-2476. https://doi.org/ 10.37358/RC.19.7.7363

[11] Mihalache G, Buhaş C, Rahotă D. Medical and social implications of suicide in youth. Holistic study of cases in Bihor County 2007-2009. Rom J Leg Med, 2011, 19(1):69-72. https://doi.org/10.4323/rjlm.2011.69

[12] Judea-Pusta CT, Muţiu G, Paşcalău AV, Buhaş CL, Ciursaş AN, Nistor-Cseppento CD, Bodea A, Judea AS, Vicaş RM, Dobjanschi L, Pop OL. The importance of the histopathological examination in lethal acute intoxication with ethylene glycol. Case report. Rom J Morphol Embryol, 2018, 59(3):965-969. PMID: 30534841

[13] Gooding HC, Milliren CE, Austin SB, Sheridan MA, McLaughlin KA. Child abuse, resting blood pressure, and blood pressure reactivity to psychosocial stress. J Pediatr Psychol, 2016, 41(1):5-14. https://doi.org/10.1093/jpepsy/jsv 040 PMID: 25979082 PMCID: PMC4723669

[14] Stoicescu M, Csepento C, Muţiu G, Bungău S. The role of increased plasmatic renin level in the pathogenesis of arterial hypertension in young adults. Rom J Morphol Embryol, 2011 , 52(1 Suppl):419-423. PMID: 21424086

[15] Găman MA, Dobrică EC, Pascu EG, Cozma MA, Epîngeac ME, Găman AM, Pantea Stoian AM, Bratu OG, Diaconu CC. Cardiometabolic risk factors for atrial fibrillation in type 2 diabetes mellitus: focus on hypertension, metabolic syndrome and obesity. J Mind Med Sci, 2019, 6(1):157-161 [Article 24]. https://doi.org/10.22543/7674.61.P157161

[16] Blaze J, Roth TL. Caregiver maltreatment causes altered neuronal DNA methylation in female rodents. Dev Psychopathol, 2017 29(2):477-489. https://doi.org/10.1017/S0954579417000128 PMID: 28401839 PMCID: PMC5508559

[17] Jurcă AD, Kozma K, loana M, Streaţă I, Petcheşi CD, Bembea M, Jurcă MC, Cuc EA, Vesa CM, Buhaş CL. Morphological and genetic abnormalities in a Jacobsen syndrome. Rom J Morphol Embryol, 2017, 58(4):1531-1534. PMID: 29556653

[18] Bartlett JD, Kotake C, Fauth R, Easterbrooks MA. Intergenerational transmission of child abuse and neglect: do maltreatment type, perpetrator, and substantiation status matter? Child Abuse Negl, 2017, 63:84-94. https://doi.org/ 10.1016/j.chiabu.2016.11.021 PMID: 27914238

[19] Abrahams N, Mathews S, Martin LJ, Lombard C, Nannan N, Jewkers R. Gender differences in homicide of neonates, infants, and children under 5 y in South Africa: results from the cross-sectional 2009 National Child Homicide Study. PLoS Med, 2016, 13(4):e1002003. https://doi.org/10.1371/journal. pmed.1002003 PMID: 27115771 PMCID: PMC4846035
[20] Pierce MC, Kaczor K, Acker D, Webb T, Brenzel A, Lorenz DJ, Young A, Thompson R. History, injury, and psychosocial risk factor commonalities among cases of fatal and near-fatal physical child abuse. Child Abuse Negl, 2017, 69:263-277. https://doi.org/10.1016/j.chiabu.2017.04.033 PMID: 28500923

[21] Hwa HL, Pan CH, Shu GM, Chang CH, Lee TT, Lee JCI. Child homicide victims in forensic autopsy in Taiwan: a 10-year retrospective study. Forensic Sci Int, 2015, 257:413-419. https://doi.org/10.1016/j.forsciint.2015.10.020 PMID: 26562789

[22] Judea Pusta CT, Bungau S, Buhas CL, Popa AR, Vesa CM Buhas BA, Bardaca (Urducea) C, Tit DM, Daim MA, Judea AS. Experimental study upon the virulence of infectious microbial agents involved in violent deaths presenting septic states. Rev Chim (Bucharest), 2019, 70(8):2720-2726. https://doi.org/ 10.37358/RC.19.8.7415

[23] Buhaş CL, Mihalache G, Judea-Pusta CT, Buhaş B, Jurcă MC, lovan $C$. Lethal cranio-cerebral traumatism resulting through a very rare mechanism. Rom J Leg Med, 2018, 26(3):249_ 252. https://doi.org/10.4323/rilm.2018.249

[24] Buhaş CL, Mihalache GC, Judea-Pusta CT, Daina LG, Muțiu G, Buhaş BA, Popa AR, Jurcă MC, Nicoară ND, Maghiar AM. The importance of the histopathological examination in establishing the diagnosis of delayed splenic rupture. Report of a case and literature review. Rom J Morphol Embryol, 2019, 60(1): 281-286. PMID: 31263857

[25] Hicks RA, Gaughan DC. Understanding fatal child abuse. Child Abuse Negl, 1995, 19(7):855-863. https://doi.org/10. 1016/0145-2134(95)00044-9 PMID: 7583743

[26] Gilliland MG, Luckenbach MW, Chenier TC. Systemic and ocular findings in 169 prospectively studied child deaths: retinal hemorrhages usually mean child abuse. Forensic Sci Int, 1994, 16(68):117-132. https://doi.org/10.1016/0379-0738(94) 90309-3 PMID: 7988965

[27] Durfee MJ, Gellert GA. Origins and clinical relevance of child death review teams. JAMA, 1992, 267(23):3172-3175. https:// doi.org/10.1001/jama.1992.03480230064029 PMID: 1593738

[28] Ewigman B, Kivlahan C, Land G. The Missouri Child Fatality Study: underreporting of maltreatment fatalities among children younger than five years of age, 1983 through 1986. Pediatrics, 1993, 91(2):330-337. https://doi.org/ PMID: 8424006

[29] ${ }^{* * *}$. Law No. 272/2004, republished, on the protection and promotion of the rights of the child. Chapter VI: Protection of the child against abuse, neglect, exploitation and any form of violence. Section 3: Protection of the child against abuse or neglect. Official Gazette of Romania, No. 159, March 5, 2014, available at: http://www.mmuncii.ro/j33/images/Docu mente/Legislatie/L272-2004-R.pdf (accessed: November 9, 2019) (in Romanian).

[30] Fornes P, Druilhe L, Lecomte D. Childhood homicide in Paris, 1990-1993: a report of 81 cases. J Forensic Sci, 1995, 40(2): 201-204. PMID: 7602277

[31] Buhas C, Mihalache G, Buhas B, Bungau S. The difficulty in establishing the generating mechanism of cranial and vertebral lesions in a cadaver partially skeletonised. Rom J Leg Med, 2016, 24(4):300-303. https://doi.org/10.4323/rjlm. 2016.300

[32] Smithey M. Infant homicide: victim/offender relationship and causes of death. J Fam Violence, 1998, 13(3):285-297. https:// doi.org/10.1023/A:1022893006595

[33] Schmidt P, Grass H, Madea B. Child homicide in Cologne (1985-1994). Forensic Sci Int, 1996, 79(2):131-144. https:// doi.org/10.1016/0379-0738(96)01900-7 PMID: 8698292

\section{Corresponding authors}

Camelia Liana Buhaş, Associate Professor, MD, PhD, Dr. Hab., Department of Morphological Disciplines, Faculty of Medicine and Pharmacy, University of Oradea, 1 Universităţii Street, 410087 Oradea, Bihor County, Romania; Phone +40742-756 540, e-mail: cameliabuhas@yahoo.com

Simona Gabriela Bungău, Professor, PhD, Dr. Hab., Department of Pharmacy, Faculty of Medicine and Pharmacy, University of Oradea, 1 Universităţii Street, 410087 Oradea, Bihor County, Romania; Phone +40726-776 588, e-mail: simonabungau@gmail.com 